\title{
O SHOKONSAI COMO PROJETO IDENTITÁRIO
}

\author{
Aline Yuri Hasegawa ${ }^{1}$, PCHS/UFABC (CAPES) \\ Orientadora: Marilda Aparecida de Menezes
}

\section{RESUMO}

Neste paper pretendo apresentar de que maneira o projeto identitário da comunidade japonesa de Álvares Machado-SP, município próximo de Presidente Prudente-SP, ancora-se em aspectos religiosos, que se materializam no ritual Shokonsai. Para tanto, discorrerei sobre o processo histórico de formação desta comunidade, bem como suas clivagens e conflitos internos, além de sua forma de organização social e distribuição de recursos. Neste sentido, será problematizado também de que maneira esta noção de "comunidade" opera interna e externamente a identidade japonesa e delimita quem é e quem não é portador de seus sinais de marcação. Posteriormente, abordarei alguns aspectos principais do ritual Shokonsai, que é realizado anualmente em homenagem aos ancestrais desta comunidade, em um cemitério étnico mantido por sua Associação. Tal ritual é praticado há 95 anos e é o resultado histórico da imigração de japoneses para o Brasil, que trazem a cosmologia, conceitos e modos de pensamento nativos japoneses e são confrontados com a necessidade de elaborar estratégias de reprodução cultural.

Palavras-chave: ritos fúnebres, Álvares Machado-SP, comunidade japonesa

\section{CONTEXTUALIZAÇÃO}

O município de Álvares Machado-SP fica localizado no extremo oeste do Estado de São Paulo-SP, vizinho do município de Presidente Prudente -SP, capital regional da microrregião onde o município se insere (Cf.: http://www.alvaresmachado.sp.gov.br/arquivos/historia.pdf, acesso em 20 de março de 2016.).

Limita-se ao Norte como município de Alfredo Marcondes, ao Sul com os municípios de Tarabay e Pirapozinho, a Leste com o município de Presidente Prudente e ao Oeste como município de Presidente Bernardes, localizado entre as coordenadas geográficas $22^{\circ} 04^{\prime} \mathrm{S}$ e $51^{\circ} 28^{\prime} \mathrm{W}$. (TAKENAKA, 2003)

O processo de colonização oficial do território ${ }^{2}$ de Álvares Machado-SP acompanha a construção da Estrada de Ferro Sorocabana, que foi construída no final do século XIX, saindo da capital São Paulo-SP, em direção ao município de Sorocaba-SP,

\footnotetext{
${ }^{1}$ Contato: a.hasegawa@ufabc.edu.br

2 Optei por utilizar o termo "território" em detrimento de "município" uma vez que naquele momento, tais localizações geográficas não estavam organizadas de tal maneira, conhecendo os mecanismos do Estado, em geral, somente depois da chegada das estações de trem.
} 


\section{SEMINÁRIO DE PESQUISA EM CIÊNCIAS HUMANAS - SEPECH \\ Humanidades, Estado e desafios didático-científicos \\ Londrina, 27 a 29 de julho de 2016}

expandindo-se posteriormente em direção a Presidente Prudente-SP e alcançando demais territórios localizados no extremo oeste paulista. No geral, o processo de instalação das estações ferroviárias antecedia e incentivava a formação de núcleos urbanos regionais, uma vez que facilitava a chegada e saída de bens e mercadorias, a comunicação e o transporte de pessoas ${ }^{3}$.

Durante o período da ocupação deste território, suas terras eram conhecidas pelo nome de Brejão, termo que é muito encontrado nos textos históricos mencionados acima (MIYASHITA, 1968; TAKENAKA, 2003; SUZUKI, 2008) e fazia fronteira com territórios nomeados de Vai e Vem, atual município de Indiana-SP (a que os imigrantes japoneses se referiam de Bai e Bem, em decorrência da dificuldade de pronunciar os fonemas associados à letra $\mathrm{V}$, inexistente até então na língua japonesa) e Veado (onde atualmente fica Presidente Prudente-SP).

Abaixo, é possível visualizar a localização (em vermelho) do município de Álvares Machado-SP no estado de São Paulo:

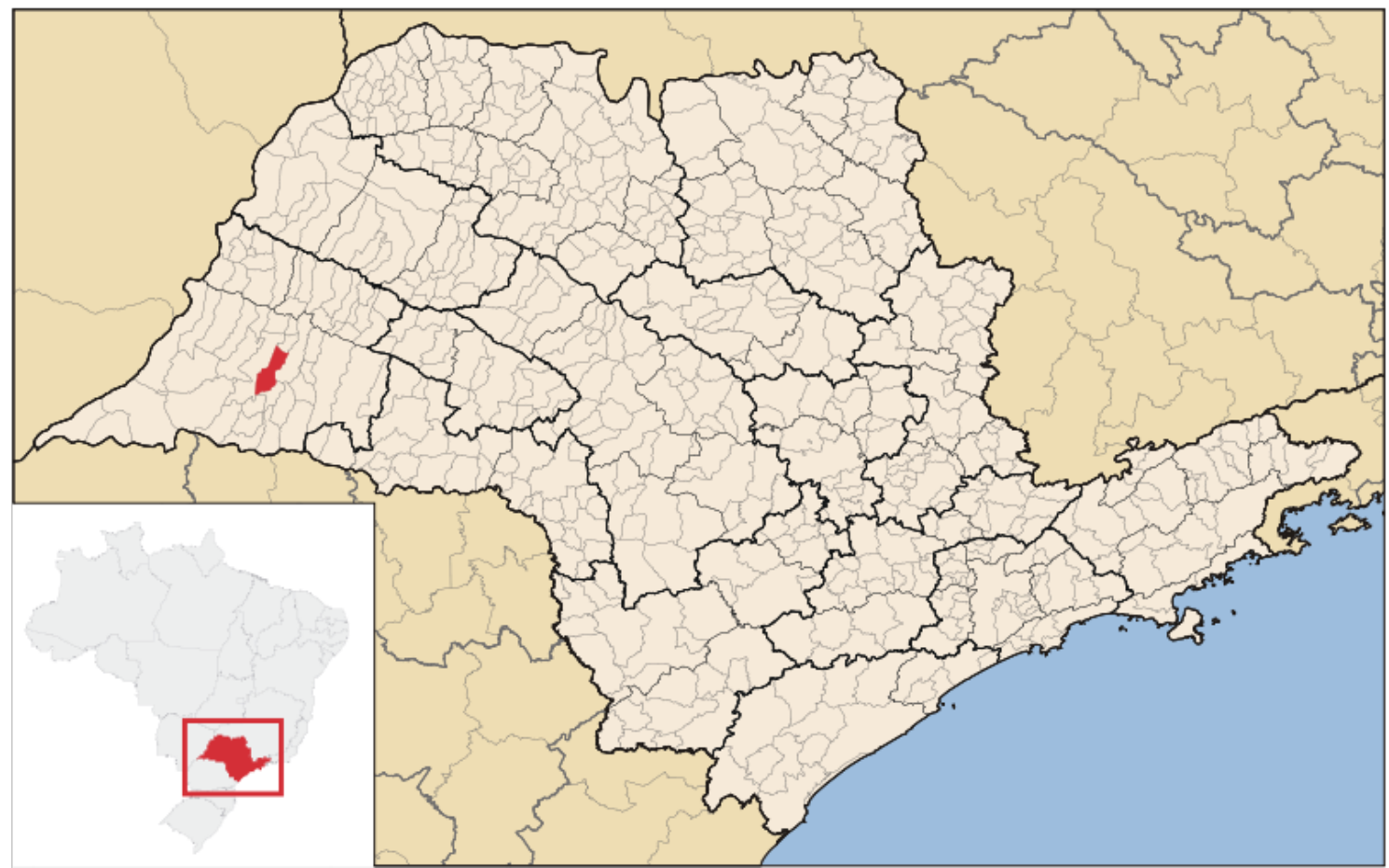

Ref.: https://pt.wikipedia.org/wiki/Ficheiro:SaoPaulo_Municip_AlvaresMachado.svg, acesso em 22 de março de 2016.

Quando comparada a outras associações de imigrantes japoneses e descendentes no Brasil, a de Álvares Machado ocupa uma posição peculiar, não somente em decorrência de ser mantenedora de um cemitério étnico que durante muito tempo foi considerado exclusivo de toda a América Latina, mas também por promover anualmente, há 95 anos, um ritual de culto aos ancestrais, nomeado Shokonsai. Talvez em decorrência da migração de um clã completo para o Brasil é que a colônia japonesa

3 Tal processo também ocorreu em diversos municípios que têm seu desenvolvimento associado à construção da Estrada de Ferro Paulista (HASEGAWA, 2013). 


\section{SEMINÁRIO DE PESQUISA EM CIÊNCIAS HUMANAS - SEPECH \\ Humanidades, Estado e desafios didático-científicos \\ Londrina, 27 a 29 de julho de 2016}

de Álvares Machado-SP apresente características tão peculiares quando comparada a outras colônias, pois confio que eles trouxeram também uma maneira de organizar as trocas de informações e recursos pelo território que opera até os dias atuais, chamado shibu.

\section{SHIBUS, NIKKAI, FUJINKAI E A NOÇÃO DE OBRIGAÇÃO}

Os shibus estão descritos em Takenaka (2003) e Miyashita (1968) e podem ser definidos como formas de organização social e de distribuição de recursos baseadas em relações de vizinhança e reciprocidade, em que o território, como localização, opera como fator fundamental na estruturação das relações sociais.

A Colônia Brejão era comumente denominada como área de 3.000 alqueires ao sul da estrada de ferro e Área de 2.000 alqueires a leste da estrada de ferro.

Essas áreas foram divididas em lotes e vendidas aos colonos japoneses e, de acordo coma proximidade das propriedades, as famílias agrupavamse em núcleos chamados de Shibu 1, Shibu 2, Shibu 3 chegando até Shibu 16. TAKENAKA, 79)

Os shibus explicitam processos de territorialização, uma vez que sua estrutura nuclear congregava famílias e vizinhos em torno de uma associação central e uma escola. Na associação, eram realizadas festividades relacionadas ao calendário anual (comemoração do ano novo, dia das mães, dia dos pais, $O$-bon, gincanas etc.), encontros casuais (almoços ou jantares semanais, por exemplo), reuniões políticas, práticas esportivas etc. e na escola, em especial, era ensinada a língua japonesa e uma espécie de "educação moral e cívica", em que os alunos aprendiam basicamente comportamentos esperados em comunidade, como por exemplo, o zelo pelo patrimônio comunitário e o comprometimento com atividades coletivas.

Ainda, cada shibu constituía um ponto nodal de uma rede maior em torno da qual as famílias trocavam receitas culinárias, alimentos, conhecimentos e saberes sobre o novo ambiente, ajuda mútua em trabalhos agrícolas, festividades e eventos fúnebres. Constituíam-se assim, alianças e afinidades baseadas nas relações de reciprocidade, que tinham como elemento organizador a estrutura ramificada dos shibus.

De acordo com minha pesquisa de mestrado e minha memória pessoal como membro de comunidade japonesa e associada aos clubes, é possível afirmar que em outros locais do Brasil que receberam colonização japonesa, havia uma organização semelhante à de Álvares Machado-SP, talvez com outra nomeação que não shibu [市部].

No entanto, principalmente no contexto do estado de São Paulo, logo após o período de modernização da agricultura paulista, que ocasionou a perda da qualidade de vida no campo ${ }^{4}$, muitos sitiantes japoneses de vários pontos do estado deixaram

\footnotetext{
${ }^{4}$ Em Hasegawa (2013) e Santos e Hasegawa [no prelo] discorro sobre os pormenores do processo, focando em estudos de caso de famílias que vivenciaram a modernização da agricultura e consequente transformação de seus modos de vida, bem como no desaparecimento de bairros rurais étnicos, marca histórica do momento anterior à modernização da agricultura.
} 


\section{SEMINÁRIO DE PESQUISA EM CIÊNCIAS HUMANAS - SEPECH \\ Humanidades, Estado e desafios didático-científicos \\ Londrina, 27 a 29 de julho de 2016}

(vendendo, arrendando ou apenas indo morar na zona urbana municipal) suas propriedades rurais e passaram a viver em centros urbanos, de modo a ficarem mais próximos das escolas e com acesso mais fácil a estradas e meios de comunicação. Tal mudança no perfil de moradia implicou em um processo de transformação também nas associações: se, mesmo vinculadas a uma associação central, antes elas também eram fortemente ativas no nível local e congregavam um pequeno número de núcleos familiares rurais; nesse novo momento, elas se aglutinavam em uma grande e forte associação de todo o município, num número muito maior de famílias congregadas em um só local e de uma só vez.

Tal mudança também ocorreu em Álvares Machado-SP, mas em decorrência das características históricas do município ${ }^{5}$ e dos processos sociais que permearam as relações tecidas dentro dos grupos, alguns shibus continuam realizando suas tarefas até hoje, mesmo estando centralizados na associação municipal.

Obedecendo à regra social de hierarquização por idade (estando os mais velhos no topo e os mais jovens abaixo); gênero (homens acima de mulheres); e raça (em que se obedece à gradação: japoneses nativos, descendentes de japoneses, mestiços e gaijins), os kais (também chamados de nihonjinkai, nikkai, clube de japoneses ou kaikan) são estruturados.

\section{Nihonjinkai}

Esta é uma instituição social que pode ser considerada tão fundamental quanto o ie, pois o kai marca a presença coletiva da comunidade japonesa onde quer que esteja instalada e é o principal veículo de troca de informações para dentro da comunidade (capilarizando-a como descrito anteriormente) e para fora (sendo seu representante coletivo oficial e mais legitimado).

\section{Fujinkai}

No caso do kai de Álvares Machado, o clube das senhoras (fujinkai - 婦人会), como nativamente é conhecido, tem sua receita separada do kai e é composto, em sua grande maioria, por mulheres, oriundas da primeira ou segunda geração de imigrantes japoneses, que residem ou residiram durante algum tempo de suas vidas em áreas rurais, com experiência de trabalho rural, pouca escolaridade; por volta de 65-90 anos.

De acordo com as observações da pesquisa e também das conversas que tive com interlocutoras, o sentimento de "obrigação" era o que fundamentava a adesão às práticas do kai. Neste sentido, a obrigação, na acepção nativa, não é como no sentido corriqueiro, coloquial: um peso, ou um fardo que se carrega e que logo que se vê livre, a pessoa se liberta e não mais realiza tal ação. No caso destas senhoras, a obrigação se traduz melhor no sentido de necessidade: sentem que precisam realizar tais tarefas. Assim como cuidar da casa, educar os filhos, zelar pelo bem estar, asseio e alimentação

\footnotetext{
${ }^{5} \mathrm{Em}$ decorrência da especificidade histórica local, muitas famílias de Álvares Machado-SP relatam não terem deixado suas moradias rurais pois seus filhos encontraram ensino superior logo no município vizinho, em Presidente Prudente-SP e também, posteriormente, no momento da saída para o mercado de trabalho, também o encontraram neste município, que dista somente $15 \mathrm{~km}$ de Álvares Machado-SP e é polo regional de serviços, educação e política. Ademais, novamente pela proximidade com um centro urbano provedor de serviços como saúde de qualidade, muitos casais e famílias que se mudaram para a cidade de São Paulo em busca de educação superior e melhores empregos, ao se aposentarem, retornam para Álvares Machado-SP, sua cidade de origem, para viverem com mais "qualidade de vida" na zona rural do município.
} 


\section{SEMINÁRIO DE PESQUISA EM CIÊNCIAS HUMANAS - SEPECH \\ Humanidades, Estado e desafios didático-científicos \\ Londrina, 27 a 29 de julho de 2016}

de todos os residentes de seu lar, tais "obrigações", ou tarefas femininas se ramificam para o kai, que é uma extensão de sua família na comunidade.

Assim, uma casa com um patriarca que participe ativamente das atividades do kai implica que a matriarca também se engaje nas atividades daquilo que concerne ao seu gênero. De modo que uma matriarca cujo marido não esteja vinculado ao kai não sentirá das demais associadas do fujinkai o mesmo apreço que sentiria se seu marido fosse membro ativo do kai, e ela conquistará pouco capital simbólico nestes ambientes, mesmo trabalhando mais do que outras, ou se doando mais do que outras, porque o que está constantemente em pauta não é o empenho individual, mas o comprometimento familiar no projeto comunitário.

Aos filhos, caso ainda residam com os pais, é reservada uma figura de apêndice. Os mais jovens quase não tem poder de direção e agem dentro de limites rígidos e estreitos, cuidando basicamente de departamentos esportivos, que têm receitas subordinadas ao kai e da barraca de bebidas, pastéis e churrasquinho toda vez que ocorre um evento social.

A noção de obrigação, que permeia todos os elementos familiares e fundamenta a ação voluntária nas atividades do kai, é a principal palavra mobilizada quando relatam as motivações para a construção e manutenção do cemitério étnico de imigrantes japoneses de Álvares Machado-SP.

Por volta do começo do século XX, antes da construção do cemitério, que fica localizado no ichi-shibu (Shibu 1), a cada vez que alguém falecia, era necessário transportar o corpo até o cemitério de Presidente Prudente-SP, que ficava localizado a $20 \mathrm{~km}$ aproximadamente. Como o atendimento à saúde era precário, era comum que pessoas falecessem por motivos banais:

O problema para os colonizadores era a falta de médicos. Havia médico da empreiteira construtora da ferrovia, mas vinha apenas uma vezes por semana, sem data marcada. Mesmo conseguindo consulta médica, para comprar os remédios era preciso ir até Assis, pois não havia farmácia. (MIYASHITA, 1968, p. 13)

$\mathrm{Na}$ época, eram necessários dois homens adultos para dar cabo da atividade, uma vez que o trajeto era realizado a pé, em meio à mata. Tal empreita ainda durava dois dias: um para ir com o corpo e o outro para retornar. Era comum, por exemplo que, assim que a dupla retornasse do cemitério, outro falecimento ${ }^{6}$ ocorresse e fosse necessário repetir o trajeto sem descanso. De acordo com Takkon, "A estrada era 'picada', duas pessoas transportavam o caixão por 15 quilômetros, revezando. Não era fácil, pois não haviam muitas pessoas disponíveis. Apenas 6 ou 7 pessoas." (p. 14)

O hakamairi denomina um ritual de culto aos ancestrais e é uma expressão que pode ser traduzida como "visitas a sepulturas" (haka [墓] significa sepultura, túmulo, mas também é utilizado para designar cemitério; e mairi [参] significa participar, fazer

6 Esse era um período marcado fortemente pelo falecimento de crianças, grávidas e idosos, grupos que ficam mais vulneráveis a sucumbirem perante doenças contagiosas em situações de desnutrição. Tal era a pobreza em que as pessoas viviam no período que muitas mães perdiam seus bebês por não produzirem leite o suficiente para amamentálos. 


\section{SEMINÁRIO DE PESQUISA EM CIÊNCIAS HUMANAS - SEPECH \\ Humanidades, Estado e desafios didático-científicos \\ Londrina, 27 a 29 de julho de 2016}

parte de, visitar). A expressão hakamairi [墓参] é procedida pelo verbo suru (que significa fazer, praticar) e no Brasil, a expressão utilizada correntemente é a tradução do verbo e a manutenção do nome do ritual - prática corrente na linguagem dos imigrantes japoneses no Brasil - seria, portanto, hakamairi suru ou "fazer hakamairi".

O O-bon (お盆, ou festival das lanternas, dos mortos), no contexto brasileiro, é um evento organizado pelas associações de cultura japonesas, engajando suas lideranças e membros ativos. Ele tem um caráter público quando comparado ao hakamairi, uma vez que este é organizado e realizado por familiares e amigos próximos do falecido. Nos O-bons são convidadas personalidades "de fora" - membros e lideranças de outros kais ([会] associação, sociedade, encontro), figuras públicas da localidade, alianças importantes para a comunidade local. Ademais, o O-bon é um dos eventos anuais que alguns kais organizam para atrair receitas, já que o público não se restringe somente aos membros da comunidade e determinadas lideranças e alianças, mas também ao município em geral. Seguindo as datas das comemorações do $O$-bon no Japão, no Brasil também são realizados em julho ou agosto.

No caso do O-bon realizado no município de Álvares Machado-SP, além das especificidades listadas acima e que serão detalhadas posteriormente, ainda há algumas características que o tornam peculiar quando comparado com os demais festivais realizados em outros municípios do Brasil. Neste local, a festa é realizada em parte no haka e em parte em um terreno grande que fica em frente à escola. As festividades ocorrem durante o dia, iniciando-se com uma missa em homenagem à memória dos ancestrais e, no final do dia, há o espetáculo de acendimento de velas nos túmulos. Este cemitério étnico nikkei, cuja manutenção é de responsabilidade do kai local, é único no Brasil.

Neste contexto, funde-se ao sentido do hakamairi, o $O$-bon, que recebe o nome de Shokonsai [招魂祭]. Tal festival tem sido realizado há 95 anos, no mesmo local e pode ser traduzido como "Festival de Convite às Almas". Somente durante a Segunda Guerra Mundial as festividades foram interrompidas e atualmente a diretoria da associação japonesa se prepara para a comemoração do centenário do Shokonsai.

Além da periodicidade, o Shokonsai também é afamado por outras peculiaridades: jamais choveu no dia do evento, o que permitiu que as festividades ocorressem sem prejuízo de público; os ventos são interrompidos no momento de acender as velas aos ancestrais, de modo que todas ficam acesas até que a última se apague naturalmente e somente então os ventos retornam. De acordo com a organização do evento, são pelas práticas cotidianas e ritualísticas dos vivos que os mortos, todo ano, impedem os ventos e as chuvas para que sejam visitados e rememorados.

A história da realização dos Shokonsais acompanha a história do cemitério. O Shokonsai é realizado na segunda semana de julho há quase um século (em 2015 foi realizado o 95). O segundo domingo de julho é o mesmo dia em que ocorre o O-bon em lugares do Japão que seguem o calendário antigo, o lunar. Nos lugares do Japão onde o O-bon é realizado em agosto, segue-se o calendário solar. A primeira comemoração do Shokonsai ocorreu em 1920, ou seja, dois anos após a institucionalização do cemitério. De acordo com o Takkon, "de 70 a 80 famílias japonesas no Brejão, pouco a pouco começaram a manifestar a vontade de fazer uma celebração para os mortos" (MIYASHITA, 1968, p.15) 


\section{SEMINÁRIO DE PESQUISA EM CIÊNCIAS HUMANAS - SEPECH \\ Humanidades, Estado e desafios didático-científicos \\ Londrina, 27 a 29 de julho de 2016}

Neste dia, as almas dos antepassados retornam à terra para matar as saudades de seus parentes, além disso, é um dia de suas vidas que os vivos dedicam à rememoração dos mortos e do agradecimento por suas vidas. Por isso, é importante ir aos cemitérios - onde as pessoas estão enterradas e para onde as suas almas retornam no dia do O-bon.

\section{REFERÊNCIAS}

HASEGAWA, A. Y. De escuro a escuro: terra, trabalho e memória nikkei no município de Lucélia-SP. São Carlos-SP: UFSCar, v. dissertação (Mestrado), 2013. 277 p.

MIYASHITAA, R. Takkon. Tradução de Ligia Tamura OZAKI. São Paulo-SP: Paulista, v. Tradução 1999, 1968.

SUZUKI, J. P. Álvares Machado, uma saga japonesa. Álvares Machado-SP: /do autor, 2008.

TAKENAKA, E. M. M. Raízes de um povo: a colônia japonesa de Álvares MachadoSP. Presidente Prudente-SP: Dissertação de Mestrado, v. Mestrado em Geografia, FCT/UNESP, 2003. 